\title{
Utilization of Antenatal Care, Skilled Birth Assistant and Institutional Delivery in Bangladesh
}

\author{
A H M Musfiqur Rahman Nabeen, Nur-E-Jannat and Md. Abdus Salam Akanda* \\ Department of Statistics, Dhaka University, Dhaka 1000, Bangladesh \\ ( Received: 30 May 2017 ; Accepted : 31 October 2017)
}

\begin{abstract}
Maternal mortality is an important phenomenon to assess the overall health status of a society. To reduce maternal mortality the worldwide recognized vital three factors are: antenatal care, presence of skilled birth assistance and selection of place of delivery. This study made an initiative to identify potential risk factors which can influence the three factors employing the Bangladesh Demographic and Health Survey (BDHS), 2014 data. The parameters are estimated using Poisson count model and Logistic regression model. The estimation results indicate that mother's education level, place of residence, mother's age at birth, wealth index, husband's education level, media exposure and region are significant factors for antenatal care visits. The significant factors for skilled birth assistance are mother's education level, place of residence, wealth index, media exposure and husband's education level where as place of residence, mother's education level, wealth index, media exposure and husband's education level are significant factors for selection of place of delivery. These results may help the policy makers to develop policies that may facilitate the reduction of maternal mortality in Bangladesh.
\end{abstract}

Keywords: Antenatal care, Skilledbirth assistance, Place of delivery, Poisson count model, Logistic regression model.

\section{Introduction}

The degree of socio-economic development of a country is reflected by its maternal mortality rate (MMR). Every year many mothers die because of pregnancy related complications as they do not have proper consciousness about the care of pregnancy period. Besides many are dying at the time of delivery because of their reluctance of giving institutionalized delivery provided with necessary medical facilities. According to the world health statistics ${ }^{1}, \mathrm{MMR}$ per 100,000 live births was estimated at 216 globally in the year 2015. Most of these deaths occur in the developing countries ${ }^{1}$. Thus as a developing country, maternal mortality deserves a high attention from the government as well as from the researchers of Bangladesh. When a woman dies in the process of giving birth of a child, her child and survival of any other children are endangered seriously and the whole family becomes vulnerable. Children are less chance to be immunized without mothers and are more chance to be malnourished. Besides infants without mothers are more likely to die i.e., the unexpected maternal mortality causes child mortality which has another ominous impact on the society. That is why for the welfare of the overall health condition including child mortality any developing countries like Bangladesh should start from reducing maternal mortality.

Maternal deaths are mainly classified as direct and indirect obstetrical deaths. Direct obstetrical deaths occur due to obstetric complications of maternity. They are generally one of the five major reasons: hemorrhage, eclampsia, sepsis, complications of obstructive labor and insecure miscarriage ${ }^{2}$. Indirect obstetrical deaths occur due to diseases that were existed in the pastor from diseases occurring during the period of pregnancy (but without direct obstetrical causes). The most important indirect causes are malnutrition, anaemia, malaria, hepatitis, heart diseases, tuberculosis or $\mathrm{HIV}^{2}$. Existing literatures ${ }^{3-12}$ suggest that antenatal care (ANC), presence of skilled birth assistance (SBA) and selection of place of delivery (PoD) have direct association with direct obstetric maternal deaths. Hossain et $a l .^{3}$, Islam et al..$^{5}$, Kabir et al. ${ }^{9}$ and Akanda ${ }^{11}$ highlighted the relationship with ANC and some socio-demographic and health related factors. Goodburn et al. ${ }^{12}$ mentioned that trained birth attendants are more likely to practice hygienic delivery than those that are untrained and the probability of using a trained birth attendant at the time of delivery depends on respondent's type of residence, education, age at birth, susceptibility to media and husband's education. Akanda $^{10}$ showed that women of wealthy income quintile, mother's education, place of residence, wanted pregnancy, and those whose health information was accessed through television, delivered their children in appropriate healthcare organizations. But this study attempts to find out the potential factors of ANC, SBA and PoD simultaneously. The currently available updated data are applied for that purpose.

\section{Data and Methods}

The nationally representative secondary data extracted from Bangladesh Demographic and Health Survey (BDHS), 2014 are used for this study which was conducted by National Institute of Population Research and Training (NIPORT), of the ministry of Health and Family Welfare, Bangladesh ${ }^{13}$. Mitra and Associates, a research firm in Dhaka from Bangladesh implemented the survey. Technical support was given by Macro International Inc. in Calverton, Maryland, USA; through the MEASURE DHS program. Financial support for the survey was provided by the U.S. Agency for International Development (USAID). For conducting the survey, Bangladesh was stratified into 20 strata where each stratum is made up of enumeration areas (EAs). It followed a two-stage stratified random sampling procedure. At the first stage, the survey randomly selected 600 EAs (among them 393 in rural areas and 207 in urban areas) with probability proportional to the enumeration area size. In second stage of sampling, a systematic random sample of 30 households was selected on average from each enumeration area. Finally, from the selected households information of the interviews of 17,863 ever-married women aged 12 to 49 years was collected. The BDHS, 2014 includes their socioeconomic, bio-demographic, and maternal and child health related information.

Three response variables are considered to describe the current situation of maternal health care ${ }^{3-12}$ : number of

\footnotetext{
Author for correspondence. e-mail: akanda@du.ac.bd
} 
antenatal care visits by a mother, whether a mother received safe health care from a skilled birth attendant (yes, no), what is the place of delivery (hospital/other, home). The number of observations is 7181 for this study. In the BDHS, 2014 data $\mathrm{ANC}$ is given as count data $(0,1,2, \ldots)$. For the presence of SBA, it is considered whether women received the assistance from doctor, nurse, family welfare visitor (FWV), family welfare assistant (FWA), medical assistant/subassistant and health assistant (HA), community skill birth attendant (CSBA). If at least one of the above skilled persons present sat the time of delivery then SBA is 'yes' otherwise 'no'. In case of place of delivery there are two categories- 'yes' for the women who give birth provided with health facilities from hospitals or other institutions, and 'no' for the women who give birth in home. To investigate the demographic and socio-economic impact on the antenatal care visit, skill birth assistance during delivery and place of delivery, a total of ten independent variables ${ }^{3,5,11-}$ 12,14-16 are considered: place of residence (urban, rural), religion (other, Islam), mother's age at birth $(<20,20-30$, $30+$ ), mother's education (no education, primary, secondary, higher), wealth index (poor, middle, rich), NGO membership (yes, no), media exposure (yes, no), husband's education (no education, primary, secondary, higher), decision on respondent's health care (others, respondent alone, husband and respondent (both), husband alone), region (Barisal, Chittagong, Dhaka, Khulna, Rajshahi, Rangpur and Sylhet). It is noted that information on NGO membership of mother and exposure to mediaare indirectly collected in BDHS, 2014 survey. The variable NGO membership of mother is created if a respondent of the survey belongs to any one of the NGOs like BRAC, ASHA, Grameen Bank, BRDB, Proshika etc. As media exposure have impact on maternal issue by using the information of listening to radio/watching television, reading newspapers or magazine, the variable exposure to media is created.

\section{Poisson count model}

To find out the adjusted effects of selected covariates on ANC visits Poisson count model is fitted for the counted data of the number of ANC visits. Under the Poisson model, the response variable $\mathrm{Y}$ has a Poisson distribution. Suppose that there are $n$ independent responses $Y_{1}, \ldots, Y_{i}, \ldots, Y_{n}$ with mean number of response $\mu_{i}$. Then, the response variable $Y_{i}$ has probability mass function (pmf) of the form

$$
f\left(y_{i}, \mu_{i}\right)=\frac{e^{-\mu_{i}} \mu_{i}^{y_{i}}}{y_{i} !} ; y_{i}=0,1,2, \ldots \ldots \ldots
$$

Poisson count model is a member of generalized linear model (GLM) where log-link function is used as a link function $^{17-18}$. That is, it models the log of mean of response with the linear predictor $\eta_{i}=x_{i}{ }^{\prime} \beta$ as follows:

$$
\ln \left(\mu_{i}\right)=x_{i}^{\prime} \beta=\eta_{i}
$$

The regression model given in (i) is a Poisson count model where $x_{i}=\left(x_{i 1}, \ldots, x_{i j}, \ldots, x_{i p}\right)^{\prime}$ be the $p \times 1$ vector of covariates and $\beta=\left(\beta_{1}, \ldots, \beta_{j}, \ldots, \beta_{p}\right)^{\prime}$ be the $p \times 1$ vector of regression coefficients linked with response.

\section{Logistic regression model}

The other two response variables are SBA and PoD which have binary categories. It is assumed in logistic regression model that response variable should be binary in nature. Hence the logistic regression model is used for the purpose of modeling SBA and PoD. Suppose that there are $n$ independent responses $Y_{1}, \ldots, Y_{i}, \ldots, Y_{n}$ with probability of success $\pi_{i}$ and the probability mass function (pmf) of $y_{i}$ is

$$
f\left(y_{i}\right)=\pi_{i} y_{i}\left(1-\pi_{i}\right)^{y_{i}} ; y_{i}=0,1 ; 0<\pi_{i}<1 \text {. }
$$

Then the mean response is $E\left(y_{i}\right)=\pi_{i}$. In logistic regression model, logit link function ${ }^{18}$ is used to make a bridge between mean response $\pi_{i}$ and the linear predictor $\eta_{i}=x_{i}{ }^{\prime} \beta$ as follows:

$$
\ln \left(\frac{\pi_{i}}{1-\pi_{i}}\right)=\eta_{i}=x_{i}{ }^{\prime} \beta \text {. Or, } \pi_{i}=\frac{e^{x_{i}{ }^{\prime} \beta}}{1+e^{x_{i}^{\prime} \beta}} \ldots \ldots \ldots .
$$

The regression model given in equation (ii) is a logistic regression model where $x_{i}=\left(x_{i 1}, \ldots, x_{i j}, \ldots, x_{i p}\right)^{\prime}$ is the $p \times 1$ vector of covariates linked with response and $\beta=\left(\beta_{1}, \ldots, \beta_{j}, \ldots, \beta_{p}\right)^{\prime}$ be the corresponding vector of regression parameters.

\section{Results and Discussion}

The data analyses are conducted into three distinct categories (i) Univariate analysis, (ii) Bivariate analysis and (iii) Multivariate analysis. The results are presented below:

\section{Univariate analysis}

The percentage distribution of the covariates used in this study is shown in Table 1. It is observed that more than half of the women $(68.4 \%)$ are from rural area while $31.6 \%$ are from urban area. About $90 \%$ of them are Muslims and the rest are non-Muslims. 58.1\% mothers gave birth their first child within age groups $20-30$, while $29.2 \%$ were in age below 20 and $12.7 \%$ were in age above 30. Among all women about $18 \%$ have no education, $29.8 \%$ have primary education, $43.5 \%$ have secondary education and $8.6 \%$ have higher education. Besides $39.9 \%$ mothers are from poor family and $19.2 \%$ are from middle class family whereas $40.9 \%$ are from rich family. It is observed that the highest numbers of observations are from Chittagong division (19\%) and the lowest from Rajshahi division (13\%). Among all mothers $25.9 \%$ belong to NGO membership where $74.1 \%$ do not. On the other hand $65.5 \%$ mothers have media exposure and $34.5 \%$ do not have. About $26.6 \%$ husbands have no education, $29.1 \%$ have primary education, $30.1 \%$ have secondary education, while only $14.2 \%$ husbands have higher education. A large number of women $(50.5 \%)$ take decision on their health care with the collaboration of their husband and only $11.6 \%$ take decision alone but $31.2 \%$ women should entirely depend on their husband's decision. 
Table 1. Summary statistics of the covariates associated with ANC, SBA and PoD

\begin{tabular}{|c|c|c|c|c|c|c|c|}
\hline Variables & Category & Freq. & $\begin{array}{c}\text { Percentage } \\
(\%)\end{array}$ & $95 \% \mathrm{CI}$ & $\begin{array}{l}\text { p-value of } \\
\text { ANOVA } \\
\text { test for } \\
\text { ANC }\end{array}$ & $\begin{array}{l}\mathrm{p} \text {-value } \\
\text { of } \chi^{2} \text { test } \\
\text { for SBA }\end{array}$ & $\begin{array}{l}\text { p-value } \\
\text { of } \chi^{2} \\
\text { test for } \\
\text { PoD }\end{array}$ \\
\hline Place of residence & $\begin{array}{l}\text { Urban } \\
\text { Rural }\end{array}$ & $\begin{array}{l}2272 \\
4909\end{array}$ & $\begin{array}{l}31.6 \\
68.4\end{array}$ & $\begin{array}{l}(30.52,32.68) \\
(67.32,69.48)\end{array}$ & 0.001 & 0.001 & 0.001 \\
\hline Religion & $\begin{array}{l}\text { Others } \\
\text { Islam }\end{array}$ & $\begin{array}{r}714 \\
6467\end{array}$ & $\begin{array}{l}9.90 \\
90.1\end{array}$ & $\begin{array}{r}(9.21,10.59) \\
(89.41,90.79)\end{array}$ & 0.241 & 0.156 & 0.080 \\
\hline $\begin{array}{l}\text { Mother's age at } 1^{\text {st }} \\
\text { birth }\end{array}$ & $\begin{array}{l}\text { Age }<20 \\
\text { Age } 20-30 \\
\text { Age } 30+\end{array}$ & $\begin{array}{r}2095 \\
4172 \\
914\end{array}$ & $\begin{array}{l}29.2 \\
58.1 \\
12.7\end{array}$ & $\begin{array}{l}(28.15,30.25) \\
(56.96,59.24) \\
(11.93,13.47)\end{array}$ & 0.047 & 0.020 & 0.028 \\
\hline Mother's education & $\begin{array}{l}\text { No edu. } \\
\text { Primary } \\
\text { Secondary } \\
\text { Higher }\end{array}$ & $\begin{array}{r}1296 \\
2140 \\
3126 \\
619\end{array}$ & $\begin{array}{l}18.0 \\
29.8 \\
43.5 \\
8.60\end{array}$ & $\begin{array}{r}(17.11,18.88) \\
(28.74,30.85) \\
(42.35,44.65) \\
(7.95,9.25)\end{array}$ & 0.001 & 0.001 & 0.003 \\
\hline Wealth index & $\begin{array}{l}\text { Poor } \\
\text { Middle } \\
\text { Rich }\end{array}$ & $\begin{array}{l}2865 \\
1381 \\
2935\end{array}$ & $\begin{array}{l}39.9 \\
19.2 \\
40.9\end{array}$ & $\begin{array}{l}(38.77,41.03) \\
(18.29,20.11) \\
(39.76,42.04)\end{array}$ & 0.004 & 0.039 & 0.001 \\
\hline Belong to NGO & $\begin{array}{l}\text { No } \\
\text { Yes }\end{array}$ & $\begin{array}{l}5319 \\
1862\end{array}$ & $\begin{array}{l}74.1 \\
25.9\end{array}$ & $\begin{array}{l}(73.09,75.11) \\
(24.89,26.91)\end{array}$ & 0.034 & 0.001 & 0.046 \\
\hline Media Exposure & $\begin{array}{l}\text { No } \\
\text { Yes }\end{array}$ & $\begin{array}{l}2474 \\
4707\end{array}$ & $\begin{array}{l}34.5 \\
65.5\end{array}$ & $\begin{array}{l}(33.40,35.60) \\
(64.40,66.60)\end{array}$ & 0.003 & 0.001 & 0.001 \\
\hline Husband'seducation & $\begin{array}{l}\text { No edu } \\
\text { Primary } \\
\text { Secondary } \\
\text { Higher }\end{array}$ & $\begin{array}{l}1912 \\
2089 \\
2154 \\
1022\end{array}$ & $\begin{array}{l}26.6 \\
29.1 \\
30.1 \\
14.2\end{array}$ & $\begin{array}{l}(25.58,27.62) \\
(28.05,30.15) \\
(29.04,31.16) \\
(13.39,15.00)\end{array}$ & 0.017 & 0.035 & 0.001 \\
\hline $\begin{array}{l}\text { Decision on } \\
\text { respondent's health } \\
\text { care }\end{array}$ & $\begin{array}{l}\text { Others } \\
\text { Resp. alone } \\
\text { Both } \\
\text { Husb. alone }\end{array}$ & $\begin{array}{r}488 \\
831 \\
3625 \\
2237\end{array}$ & $\begin{array}{l}6.80 \\
11.6 \\
50.5 \\
31.2\end{array}$ & $\begin{array}{r}(6.21,7.38) \\
(10.85,12.34) \\
(49.34,51.65) \\
(30.12,32.27)\end{array}$ & 0.024 & 0.046 & 0.002 \\
\hline Region & $\begin{array}{l}\text { Barisal } \\
\text { Chitt. } \\
\text { Dhaka } \\
\text { Khulna } \\
\text { Rajshahi } \\
\text { Rangpur } \\
\text { Sylhet }\end{array}$ & $\begin{array}{r}838 \\
1361 \\
1208 \\
859 \\
936 \\
942 \\
1094\end{array}$ & $\begin{array}{l}11.7 \\
19.0 \\
16.8 \\
12.0 \\
13.0 \\
13.1 \\
14.4\end{array}$ & $\begin{array}{l}(10.96,12.44) \\
(18.09,19.91) \\
(15.94,17.66) \\
(11.24,12.75) \\
(12.22,13.77) \\
(12.31,13.88) \\
(13.58,15.21)\end{array}$ & 0.056 & 0.083 & 0.074 \\
\hline
\end{tabular}

In the case of response variables, the percentage of number of ANC visits during pregnancy period is given in Figure 1. For SBA about $37 \%$ mothers got skilled birth assistance at the time of their delivery but about $63 \%$ did not get. However, approximately $80 \%$ women gave birth at home without the health facilities if needed while only about $20 \%$ gave birth at hospital or other institution where various health facilities are available.

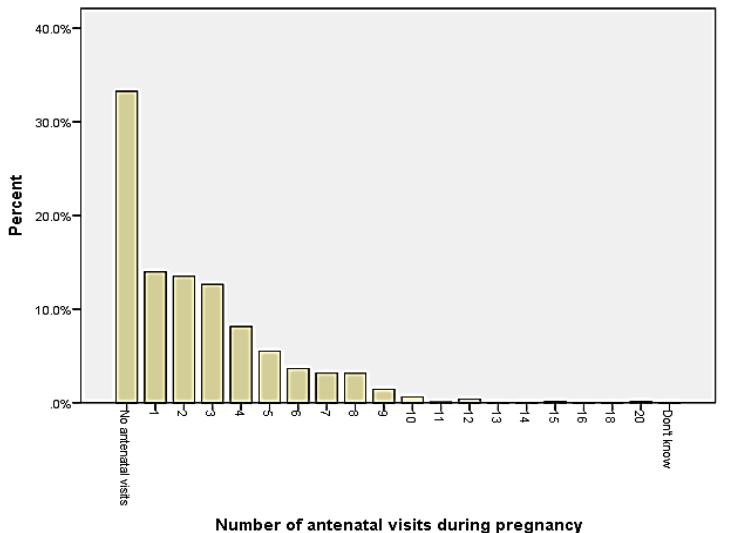

Fig 1. Percentage distribution of the number of ANC visits of women 


\section{Bivariate analysis}

An attempt has been made to find out the unadjusted association between selected covariates and ANC visits, SBA, PoD simultaneously. The results are given in Table 1. ANOVA test is applied to determine whether the average number of ANC visits is significantly associated with a specific covariate. On the other hand chi-square test is applied to find out whether a particular covariate is significantly associated with SBA or PoD. It is observed that for all covariates the average number of ANC visits differ significantly at $5 \%$ level of significance between the categories of the covariates except the covariate religion and region.The results of unadjusted association for SBA and PoD are almost similar. There is a significant association between a specific covariate and SBA orPoD for all covariates except religion and region.

\section{Multivariate analysis}

Results of Poisson count regression model

The parameter estimation results of Poisson count model are presented in Table 2. It is found that the mean number of ANC visits for women from urban area is 1.357 times higher than the rural area. The outcome is appropriate in Bangladesh as the sources of taking ANC are lower in rural areas than the urban areas. The mean number of ANC visits for the primary, secondary and higher educated mothers are $1.35,1.773$ and 2.286 times more than the non-educated mothers respectively. The mean number of ANC visits during pregnancy period is 1.147 and 1.515 times higher for the middle and rich mothers respectively in reference of poor mothers. In case of media exposure, the mean number of ANC visits is 1.224 times higher for the mothers who are exposed to media than the mothers who are not. Thus exposure to media can play a vital role in the regard of increasing ANC visits. The mean ANC visits for the women with primary, secondary and higher educated husbands are $1.086,1.184$ and 1.370 times higher respectively than the women with non-educated husbands. Hence ANC visits depend on husband's education level.

Table 2. Estimates of regression parameter $(\widehat{\boldsymbol{\beta}}), \operatorname{Exp}(\widehat{\boldsymbol{\beta}})$, Standard errors and p-value obtained using Poisson count model for ANC visits

\begin{tabular}{|c|c|c|c|c|c|}
\hline Variables & Categories & $\widehat{\boldsymbol{\beta}}$ & $\mathbf{S . E}(\widehat{\boldsymbol{\beta}})$ & $\operatorname{Exp}(\widehat{\boldsymbol{\beta}})$ & p-value \\
\hline \multirow{2}{*}{ Place of residence } & Rural (Ref.) & & & & \\
\hline & Urban & 0.278 & 0.017 & 1.357 & 0.001 \\
\hline \multirow[t]{2}{*}{ Religion } & Others (Ref.) & & & & \\
\hline & Islam & -0.148 & 0.023 & 0.862 & 0.050 \\
\hline \multirow[t]{3}{*}{ Mother's age at birth } & Age $<20$ (Ref) & & & & \\
\hline & Age $20-30$ & -0.021 & 0.017 & 0.979 & 0.330 \\
\hline & Age $30+$ & 0.002 & 0.028 & 1.002 & 0.090 \\
\hline \multirow[t]{4}{*}{ Mother's education level } & No education (Ref.) & & & & \\
\hline & Primary & 0.300 & 0.032 & 1.350 & 0.010 \\
\hline & Secondary & 0.573 & 0.033 & 1.773 & 0.002 \\
\hline & Higher & 0.827 & 0.040 & 2.286 & 0.001 \\
\hline \multirow{3}{*}{ Wealth index } & Poor (Ref.) & & & & \\
\hline & Middle & 0.137 & 0.026 & 1.147 & 0.007 \\
\hline & Rich & 0.416 & 0.025 & 1.515 & 0.000 \\
\hline \multirow[t]{2}{*}{ NGO membership } & No (Ref.) & & & & \\
\hline & Yes & -0.020 & 0.019 & 0.980 & 0.281 \\
\hline \multirow[t]{2}{*}{ Media exposure } & No (Ref.) & & & & \\
\hline & Yes & 0.202 & 0.022 & 1.224 & 0.005 \\
\hline \multirow[t]{4}{*}{ Husband education level } & No education (Ref.) & & & & \\
\hline & Primary & 0.083 & 0.026 & 1.086 & 0.002 \\
\hline & Secondary & 0.169 & 0.027 & 1.184 & 0.001 \\
\hline & Higher & 0.315 & 0.033 & 1.370 & 0.001 \\
\hline \multirow{4}{*}{$\begin{array}{l}\text { Decision on respondent's health } \\
\text { care }\end{array}$} & Others (Ref.) & & & & \\
\hline & Respondent alone & 0.014 & 0.037 & 1.014 & 0.711 \\
\hline & Both & 0.032 & 0.031 & 1.032 & 0.309 \\
\hline & Husband alone & -0.027 & 0.033 & 0.973 & 0.410 \\
\hline \multirow[t]{7}{*}{ Region } & Barisal (Ref.) & & & & \\
\hline & Chittagong & -0.206 & 0.029 & 0.814 & 0.004 \\
\hline & Dhaka & -0.051 & 0.029 & 0.951 & 0.083 \\
\hline & Khulna & 0.019 & 0.030 & 1.019 & 0.531 \\
\hline & Rajshahi & -0.036 & 0.031 & 0.965 & 0.253 \\
\hline & Rangpur & $0.260-$ & 0.029 & 1.297 & 0.013 \\
\hline & Syhlet & 0.176 & 0.032 & 0.839 & 0.007 \\
\hline
\end{tabular}




\section{Results of Logistic regression model}

To find out the adjusted effect of selected covariates on SBA and PoD logistic regression model is used. Table 3 represents the results of logistic regression model on skilled birth assistance (SBA). It is observed that urban women are 3.149 times more likely to have SBA at the time of delivery than the rural women. Primary, secondary and higher educated mothers are 1.32, 2.171 and 6.212 times more likely to take SBA during delivery than those of noneducated mothers respectively. The women who are belonging to rich and middle class family are 1.289 and 2.29 times more likely to take SBA than the poor women respectively. Women who are exposed to media have 1.473 times more probability to receive SBA than the women who are not exposed to media. Women with primary, secondary and higher educated husbands are 1.153, 1.586 and 2.633 times more probable to receive SBA than those who have non-educated husbands respectively.

The results of logistic regression model for place of delivery (PoD) are represented in Table 4. From Table 4 it is found that urban women are 1.894 times more likely to give birth at hospital or other places provided with health facilities than that of rural women.

Table 3. Estimates of regression parameter $(\widehat{\boldsymbol{\beta}}), \operatorname{Exp}(\widehat{\boldsymbol{\beta}})$, Standard errors and p-values in logistic regression model for SBA

\begin{tabular}{|c|c|c|c|c|c|}
\hline Variables & Categories & $\widehat{\boldsymbol{\beta}}$ & $\operatorname{S.E}(\widehat{\boldsymbol{\beta}})$ & $\operatorname{Exp}(\widehat{\boldsymbol{\beta}})$ & p-value \\
\hline \multirow[t]{2}{*}{ Place of residence } & Rural (Ref.) & & & & \\
\hline & Urban & 1.147 & 0.065 & 3.149 & 0.004 \\
\hline \multirow[t]{2}{*}{ Religion } & Others (Ref.) & & & & \\
\hline & Islam & -0.627 & 0.094 & 0.534 & 0.050 \\
\hline \multirow[t]{3}{*}{ Mother's age at birth } & Age $<20$ (Ref.) & & & & \\
\hline & Age $20-30$ & -0.029 & 0.067 & 0.972 & 0.666 \\
\hline & Age $30+$ & 0.088 & 0.110 & 1.091 & 0.425 \\
\hline \multirow[t]{4}{*}{ Mother's education level } & No education (Ref.) & & & & \\
\hline & Primary & 0.278 & 0.110 & 1.320 & 0.012 \\
\hline & Secondary & 0.775 & 0.112 & 2.171 & 0.004 \\
\hline & Higher & 1.826 & 0.163 & 6.212 & 0.034 \\
\hline \multirow[t]{3}{*}{ Wealth index } & Poor (Ref.) & & & & \\
\hline & Middle & 0.254 & 0.089 & 1.289 & 0.005 \\
\hline & Rich & 0.829 & 0.086 & 2.290 & 0.044 \\
\hline \multirow[t]{2}{*}{ NGO membership } & No (Ref.) & & & & \\
\hline & Yes & -0.046 & 0.071 & 0.955 & 0.519 \\
\hline \multirow[t]{2}{*}{ Media exposure } & No (Ref.) & & & & \\
\hline & Yes & 0.388 & 0.077 & 1.473 & 0.001 \\
\hline \multirow[t]{4}{*}{ Husband's education level } & No education (Ref.) & & & & \\
\hline & Primary & 0.142 & 0.092 & 1.153 & 0.123 \\
\hline & Secondary & 0.461 & 0.095 & 1.586 & 0.035 \\
\hline & Higher & 0.968 & 0.123 & 2.633 & 0.007 \\
\hline \multirow[t]{4}{*}{ Decision on respondent's health care } & Others (Ref.) & & & & \\
\hline & Respondent alone & -0.024 & 0.138 & 0.977 & 0.863 \\
\hline & Both & -0.137 & 0.116 & 0.872 & 0.238 \\
\hline & Husband alone & -0.096 & 0.120 & 0.908 & 0.424 \\
\hline \multirow[t]{7}{*}{ Region } & Barisal (Ref.) & & & & \\
\hline & Chittagong & -0.116 & 0.113 & 0.890 & 0.302 \\
\hline & Dhaka & -0.081 & 0.117 & 0.923 & 0.490 \\
\hline & Khulna & 0.624 & 0.119 & 1.866 & 0.008 \\
\hline & Rajshahi & 0.205 & 0.121 & 1.228 & 0.090 \\
\hline & Rangpur & 0.178 & 0.122 & 1.195 & 0.143 \\
\hline & Syhlet & 0.012 & 0.122 & 1.012 & 0.920 \\
\hline
\end{tabular}

The mothers with primary, secondary and higher education are $1.415,2.226$ and 5.712 times more likely to receive health facilities from hospital/other places at the time of delivery respectively than those who are non-educated. The women who are belonging to rich and middle class are 1.315 and 2.365 times more chance to give birth at hospital or clinic than those who are poor respectively. Women who are exposed to media have 1.444 times more chance to give birth at a place provided with health facility than the women who are not exposed to media. There is no significant difference about choosing the delivery place for the women with non-educated and primary educated husbands. But the women with secondary and higher educated husbands are 1.501 and 2.291 times more likely to give birth at any institution provided with necessary medical facilities than that of the women whose husbands do not have any education respectively. 
Table 4. Estimates of regression parameter $(\widehat{\boldsymbol{\beta}}), \operatorname{Exp}(\widehat{\boldsymbol{\beta}})$, Standard errors and p-values in logistic regression model for PoD

\begin{tabular}{|c|c|c|c|c|c|}
\hline Variables & Categories & $\widehat{\boldsymbol{\beta}}$ & $\operatorname{S.E}(\widehat{\boldsymbol{\beta}})$ & $\operatorname{Exp}(\widehat{\boldsymbol{\beta}})$ & p-value \\
\hline \multirow[t]{2}{*}{ Place of residence } & Rural (Ref.) & & & & \\
\hline & Urban & 0.640 & 0.066 & 1.894 & 0.022 \\
\hline \multirow[t]{2}{*}{ Religion } & Others (Ref.) & & & & \\
\hline & Islam & -0.557 & 0.095 & 0.573 & 0.340 \\
\hline \multirow[t]{3}{*}{ Mother's age at birth } & Age < 20 (Ref.) & & & & \\
\hline & Age $20-30$ & 0.032 & 0.069 & 1.032 & 0.645 \\
\hline & Age $30+$ & 0.113 & 0.113 & 1.120 & 0.315 \\
\hline \multirow[t]{4}{*}{ Mother's education level } & No education (Ref.) & & & & \\
\hline & Primary & 0.347 & 0.117 & 1.415 & 0.003 \\
\hline & Secondary & 0.800 & 0.119 & 2.226 & 0.000 \\
\hline & Higher & 1.743 & 0.162 & 5.712 & 0.000 \\
\hline \multirow[t]{3}{*}{ Wealth index } & Poor (Ref.) & & & & \\
\hline & Middle & 0.274 & 0.094 & 1.315 & 0.004 \\
\hline & Rich & 0.861 & 0.090 & 2.365 & 0.001 \\
\hline \multirow{2}{*}{ NGO membership } & No (Ref.) & & & & \\
\hline & Yes & -0.134 & 0.073 & 0.875 & 0.068 \\
\hline \multirow[t]{2}{*}{ Media exposure } & No (Ref.) & & & & \\
\hline & Yes & 0.367 & 0.081 & 1.444 & 0.044 \\
\hline \multirow[t]{4}{*}{ Husband's education level } & No education (Ref.) & & & & \\
\hline & Primary & 0.120 & 0.097 & 1.128 & 0.214 \\
\hline & Secondary & 0.406 & 0.099 & 1.501 & 0.038 \\
\hline & Higher & 0.872 & 0.125 & 2.391 & 0.049 \\
\hline \multirow[t]{4}{*}{ Decision on respondent's health care } & Others (Ref.) & & & & \\
\hline & Respondent alone & -0.056 & 0.141 & 0.946 & 0.691 \\
\hline & Both & -0.076 & 0.119 & 0.927 & 0.521 \\
\hline & Husband alone & -1.18 & 0.123 & 0.889 & 0.339 \\
\hline \multirow[t]{7}{*}{ Region } & Barisal (Ref.) & & & & \\
\hline & Chittagong & -0.163 & 0.118 & 0.849 & 0.166 \\
\hline & Dhaka & 0.119 & 0.120 & 1.126 & 0.322 \\
\hline & Khulna & 0.764 & 0.122 & 2.147 & 0.030 \\
\hline & Rajshahi & 0.393 & 0.125 & 1.481 & 0.002 \\
\hline & Rangpur & 0.357 & 0.126 & 1.429 & 0.004 \\
\hline & Syhlet & 0.074 & 0.127 & 1.077 & 0.560 \\
\hline
\end{tabular}

\section{Conclusion}

Reduction of maternal mortality deserves immense importance both domestically and internationally. If maternal mortality is unexpectedly large particularly in impoverished communities like Bangladesh, then there arises so many crises. For instance, if the government of Bangladesh can be able to reduce maternal mortality then the child mortality rate will also be controlled and the socioeconomic conditions of Bangladesh will also increase. That is why it is needed to ensure proper health care for the mothers and to reduce maternal mortality to be a prosperous country through proper antenatal care (ANC), skilled birth assistance, selection of institutional delivery provided with health facilities. Thus, the policy makers should consider these three factors meticulously. In this paper the significant factors of ANC, SBA and PoD are identified which can play an important role to increase ANC visits, to improve the percentage of taking skilled birth attendant and to increase the number of institutionalized delivery.
Some recommendations can be suggested according to the findings of the analysis:

i) Necessary maternal health care facilities should be provided in rural areas such that the number of ANC visits, SBA, PoD provided with health facilities can be increased in rural areas.

ii) Government should take necessary steps to increase the level of education of male and female as education is one of the most important factors to reduce maternal mortality.

iii) The government should provide some social security and medical support for the poor people of the society since the poor people cannot afford medical and other health related supports easily.

iv) Reading newspaper/magazine, or listening radio, or watching television should be increased as women being exposure with media have higher number of ANC visits, higher taking of SBA during pregnancy than non-exposure women. 
v) Necessary steps should be taken to increase consciousness about the importance of ANC visits during pregnancy, SBA and PoD at the delivery time and also to provide logistics supports at Chittagong, Khulna, Rangpur, and Sylhet divisions in Bangladesh to increase ANC visits, SBA and institutional delivery.

\section{Acknowledgement}

We are greatly indebted to the Department of Statistics, University of Dhaka for its logistics support. We are thankful to the National Institute of Population Research and Training (NIPORT)authorities, Bangladesh for allowing us to use BDHS, 2014.

\section{References}

1. World health statistics, 2016. Monitoring health for the sustainable development goals (SDGs).

2. Say, L., D. Chou, A. Gemmill, O. Tunçalp, A.B. Moller and J.D. Daniels, 2014. Global causes of maternal death: A WHO systematic analysis. Lancet Glob Health, 2(6), 323-333.

3. Hossain, M.K., M.R. Islam, M.N. Khan and M.R. Ali, 2015. Contribution of socio-demographic factors on antenatal care in Bangladesh: Modeling approach. Public Health Research, 5(4), 95-102.

4. Afsana, K. and S.F. Rashid, 2001. The challenges of meeting rural Bangladeshi women's needs in delivery care. Reproductive Health Matters, 9(18), 79-88.

5. Islam, M.R. and J.O. Odland, 2011. Determinants of antenatal and postnatal care visits among Indigenous people in Bangladesh: A study of the Mru community. Rural and Remote Health, 11(2), 1672.

6. Ahbab, M. F. R. and C. K. Shamal, 2015. The Socioeconomic determinants of antenatal health care utilization in Bangladesh: Evidence from multivariate techniques. Dhaka Univ. J. Sci., 63(1), 19-23.

7. Anwar, I., M. Sami, N. Akhtar, M.E. Chowdhury, U. Salma, M. Rahman and M. Koblinsky, 2008. Inequity in maternal health-care services: Evidence from home-based skilled-birth attendant programmers in Bangladesh. Bulletin of the World Health Organization, 86, 252-259.
8. Babar, T. and J. Hatcher, 2004. Health seeking behavior and health service utilization in Pakistan challenging the policy makers. Journal of Public Health, 10, 1093.

9. Kabir, R. and H.T.A. Khan, 2013. Utilization of antenatal care among pregnant women of urban slums of Dhaka city, Bangladesh. Journal of Nursing and Health Science, 2(2), 1519.

10. Akanda, M. A. S, 2012. Demand for institutional delivery in Bangladesh: An application of household production function. Dhaka Univ. J. Sci., 60(1), 53-59.

11. Akanda, M. A. S, 2010. Demand for antenatal care in Bangladesh: An application of two-part model. South Asian Journal of Population and Health, 3(1), 29-41.

12. Goodburn, E.A. and M. Chowdhury, 2000. Training traditional birth attendants in clean delivery does not prevent postpartum infection. Health Policy and Planning, 15(4), 394-399.

13. Bangladesh Demographic and Health Survey (BDHS), 2014. NIPORT, Dhaka, Bangladesh; Mitra and Associates, Dhaka/Bangladesh.

14. Chakraborty, N., M.A. Islam, I.R. Rafiqul, C. Chowdhury, W. Bari, and H.H. Halida, 2003. Determinants of the use of maternal health services in rural Bangladesh. Health Promotion International, 18(4), 327-37.

15. Khanam, M. and M.A.S. Akanda, 2007. Determinants of delivery complications in rural Bangladesh. Journal of Applied Sciences Research, 3(11), 1320-1326.

16. Akanda, M. A. S, 2007. Analysis of maternal health complication in rural Bangladesh by using GEE. Dhaka Univ. J. Sci., 55(1), 91-95.

17. Nelder, J. A. and R.W.M. Wedderburn, 1972. Generalized linear models. Journal of the Royal Statistical Society, 135(3), 370-384.

18. Nedler, J. A. and McCullagh, 1989. Generalized Linear Models. $2^{\text {nd }}$ Edition, Chapman and Hall, New York. 
